\title{
Compounds Used for 'Injection Lipolysis' Destroy Adipocytes and Other Cells Found in Adipose Tissue
}

\author{
Jürgen Janke ${ }^{a}$ Stefan Engeli ${ }^{b} \quad K^{2}$ erstin Gorzelniak ${ }^{a} \quad$ Friedrich C. Luft $^{a} \quad$ Jens Jordan $^{b}$ \\ ${ }^{a}$ Experimental and Clinical Research Center, Charité, Universitätsmedizin Berlin - Campus Buch and Max Delbrück Center for \\ Molecular Medicine, Berlin, \\ ${ }^{\mathrm{b}}$ Institut für Klinische Pharmakologie, Medizinische Hochschule Hannover, Germany
}

\section{Key Words}

Adipocytes · Preadipocytes · Lipoma · Cytolysis . Lipostabil · Phosphatidylcholine

\section{Summary}

Background: A widely applied technique to reduce subcutaneous fat pad size involves subcutaneous injection of a phosphatidylcholine preparation ('injection lipolysis'). As the mode of action is mostly unknown, we planned to study cellular effects of the particular drug used in Germany (Lipostabil ${ }^{\circledR}$ ). Methods: Human preadipocytes, adipocytes, vascular and skeletal muscle cells as well as renal epithelial cells were incubated in the compound, morphological changes were described, and cell vitality was measured. Results: A strong cytolytic effect of the compound was signified by lipid release and acridine orange staining of dying adipocyte nuclei. When the undiluted compound was used, more than $90 \%$ of cell death occurred after $90 \mathrm{~s}$ in preadipocytes, after $6 \mathrm{~min}$ in vascular smooth muscle cells, skeletal myotubes and renal epithelial cells, and after $15 \mathrm{~min}$ in adipocytes. Dilution slowed down cytolysis, but still $>50 \%$ of the cells disappeared during $30 \mathrm{~min}$ incubation. Neither osmotic effects nor differences in medium acidity were responsible for cell death. Conclusion: Injection lipolysis with phosphatidylcholine as the major injected compound reduces subcutaneous fat pad size through cell and tissue destruction. Beside the lack of a clear risk-benefit analysis, applying this technique represents off-label drug use and application of a drug by a contraindicated route.

\section{Introduction}

Large localized subcutaneous adipose tissue pads and lipomas may exert symptoms through mechanical compression of adjacent anatomical structures. Furthermore, lipomas in unfavorable locations may predispose to injuries $[1,2]$. In these cases, removal of subcutaneous fat pads is medically indicated. More commonly, however, local fat pads are removed for aesthetic reasons. Fat pads and lipomas can be removed through surgical resection, various liposuction techniques, and also external drug application [3-5]. Internal drug application, however, is one of the most widely applied and publicized treatment modalities [6-9]. The treatment involves multiple subcutaneous injections of a phosphatidylcholine preparation into the fat pad or lipoma. The methodology is often referred to as 'injection lipolysis'. The use of the technique for aesthetic reasons and the term 'injection lipolysis' itself are controversial for two reasons:

First, the drug typically used for 'injection lipolysis', Liposta$\mathrm{bil}^{\circledR}$, is currently approved in Europe in three countries (Italy, Germany, and Czech Republic). The application of Lipostabil by subcutaneous injection is listed under 'contraindications' in the product information. Instead, intravenous Lipostabil is approved only for prevention and treatment of fat embolism after large trauma or large bone surgery, and for treatment of peripheral vascular disease. In 2005, the Medicines and Healthcare Products Regulatory Agency in the UK issued a warning against the use of Lipostabil for subcutaneous injections, and the Federal Drug Administration stated on June 24, 2008 that Lipostabil solution appears to be a new drug without an approved new drug application (www.fda.gov/ora/ oasis/6/ ora_oasis_c_de.html), thus the use for injection lipolysis is prohibited in the USA. However, given the widespread use of 'injection lipolysis' as documented by newspaper advertisement and world wide web pages (e.g. www.injection-lipolysis. $n e t$ ), a widespread use must be expected.

\section{KARGER}

Fax +497614520714

Information@Karger.de

www.karger.com (c) 2009 S. Karger GmbH, Freiburg

Accessible online at:

www.karger.com/ofa 
Second, the term 'lipolysis' in a biochemical sense implies breakdown of stored triglycerides in viable adipocytes [10]. Yet the mechanism through which injection lipolysis mobilizes fat is unknown. We therefore planned to study the biochemical mode of action of this drug, which is used for injection lipolysis in Germany, in vitro in human adipocytes and preadipocytes, the main cellular targets of the technique.

\section{Material and Methods}

Lipostabil $^{\circledast}$ (Artegodan, Lüchow, Germany) contains 93\% (3-sn-phosphatidyl)-choline $(50 \mathrm{mg} / \mathrm{ml})$ from soy beans, together with desoxycholic acid, sodium hydroxide, sodium chloride, $\alpha$-tocopherol, benzyl alcohol, and ethanol. Either the undiluted solution or a 1:8 dilution in the control phosphate buffered saline (PBS, pH 7.4) were used for incubation of the various cell types described below. Human primary adipocytes and preadipocytes were isolated from subcutaneous adipose tissue obtained by abdominoplasty or liposuction at waist line, hips, or abdomen from otherwise healthy women and men on no concomitant medication (age range: 35-64 years; BMI range: $28-41 \mathrm{~kg} / \mathrm{m}^{2}$ ). All patients agreed in written form with tissue donation, and the Institutional Review Board of the Charité approved tissue sampling during surgery for in vitro experiments. In vitro differentiated immature adipocytes were obtained by stimulation of preadipocytes with a cocktail of insulin, isobutylmethylxanthine, cortisol, and triiodothyronine. Isolation of preadipocytes and mature adipocytes by collagenase digestion, cell culture conditions, and differentiation assays were described in detail previously [11]. Vascular smooth muscle cells, skeletal muscle myotubes, and renal epithelial cells were cultured under the same conditions. Adherent cells were examined under the microscope while incubated with the compound. Floating adipocytes were incubated $15 \mathrm{~min}$ in a shaking water bath at $37^{\circ} \mathrm{C}$, washed three times, and macroscopically analyzed after centrifugation $(200 \times g, 5 \mathrm{~min})$ or were stained with acridine orange and examined under the microscope. Acridine orange is a cell permeant dye that emits green fluorescence when bound to double stranded DNA (nuclei of viable cells will stain green, death cells show orange nuclei remnants). All experiments were repeated five times. Due to absence of any biochemical effects, we did not employ any statistical analysis. Instead we focused on the morphological description of the effects of the phosphatidylcholine preparation in human cells.

\section{Results}

We initially planned to determine the biochemical reactions of human primary adipocytes to incubation with a marketed phosphatidylcholine preparation approved for human use. Figure 1 shows that most of the primary cultured human adipocytes were destroyed after $15 \mathrm{~min}$ incubation with the compound and released the stored lipids into the culture medium. This strong cytolytic effect was confirmed by acridine orange staining of viable cell nuclei of mature human adipocytes, demonstrating an increase of dead cells from 0 to $>90 \%$ within $15 \mathrm{~min}$ of incubation (fig. 1). The profound adipocytolytic effect was not related to osmotic differences between the control buffer PBS (291 mOsm/kg) and the compound (309 $\mathrm{mOsm} / \mathrm{kg}$ ). However, the cytolytic effects obviated any further biochemical analysis of adipocyte metabolism as planned. Instead, we included several other human cell types in our

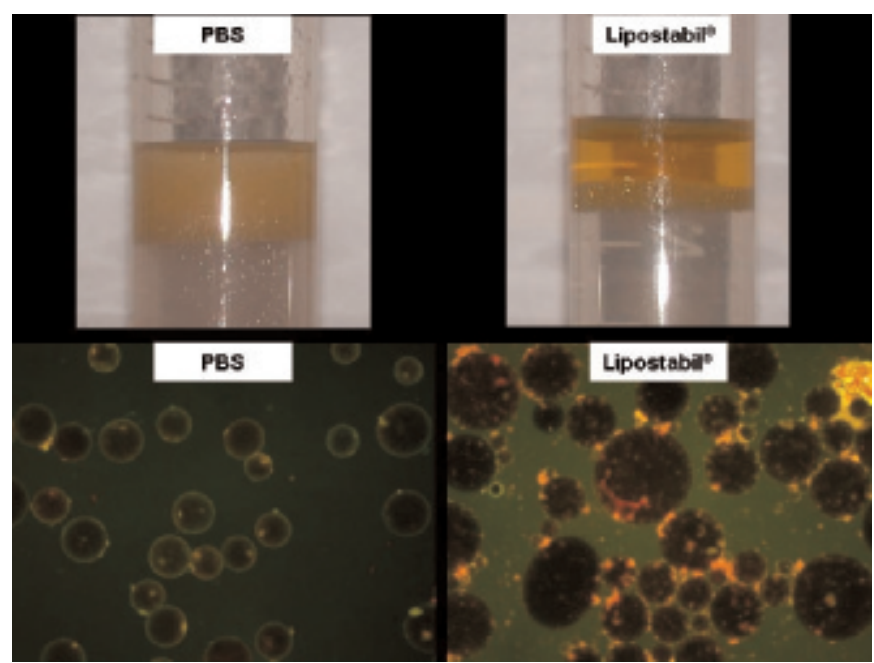

Fig. 1. Primary cultured human adipocytes were incubated for $15 \mathrm{~min}$ with PBS or Lipostabil. Upper panel: Results after a short centrifugation step. Compared to adipocytes treated with the control PBS, a thick layer of liquid oil signifies profound adipocytolysis after incubation with Lipostabil. Lower panel: Acridine orange staining demonstrates mostly viable adipocytes with green nuclei after PBS treatment, whereas adipocytes treated with Lipostabil were completely damaged, resulting in orange stained cell nuclei remnants.

experiments to determine whether mature adipocytes are especially sensitive to cytolysis. We studied primary cultured preadipocytes (devoid of any lipid droplets), in vitro differentiated immature adipocytes (visible lipid droplet accumulation), vascular smooth muscle cells, primary cultured skeletal muscle myotubes, and renal epithelial cells which are rather stable to mechanic manipulation and represent the only cell line in these experiments. Using the undiluted compound, $>90 \%$ of cell death occurred after $90 \mathrm{~s}$ in preadipocytes, after 6 min in vascular smooth muscle cells, skeletal myotubes, and renal epithelial cells, and after $15 \mathrm{~min}$ in immature adipocytes (fig. 2). Predilution by 1:8 slowed down the cytolytic effect of the compound, but still $>50 \%$ of the cells disappeared during the 30 min incubation period, irrespective of cell type (not shown). Dilution of the compound with PBS decreased $\mathrm{pH}$ from 8.0 to the physiological value of 7.4 , which excludes a predominant role of $\mathrm{pH}$ for the cytolytic effects.

\section{Discussion}

We sought after in vitro biochemical effects of a mixture compound of phosphatidylcholine, desoxycholate, $\alpha$-tocopherol, and ethanol (Lipostabil) in mature human adipocytes in order to explain the fat mass reduction after injection of this compound into lipomas. Instead we found a rather strong cytolytic effect, resulting in a large number of dead cells after incubation with the compound that obviated any further biochemical analysis. The concentrations used in vitro in our experiments do reflect the concentrations that are applied in humans or 


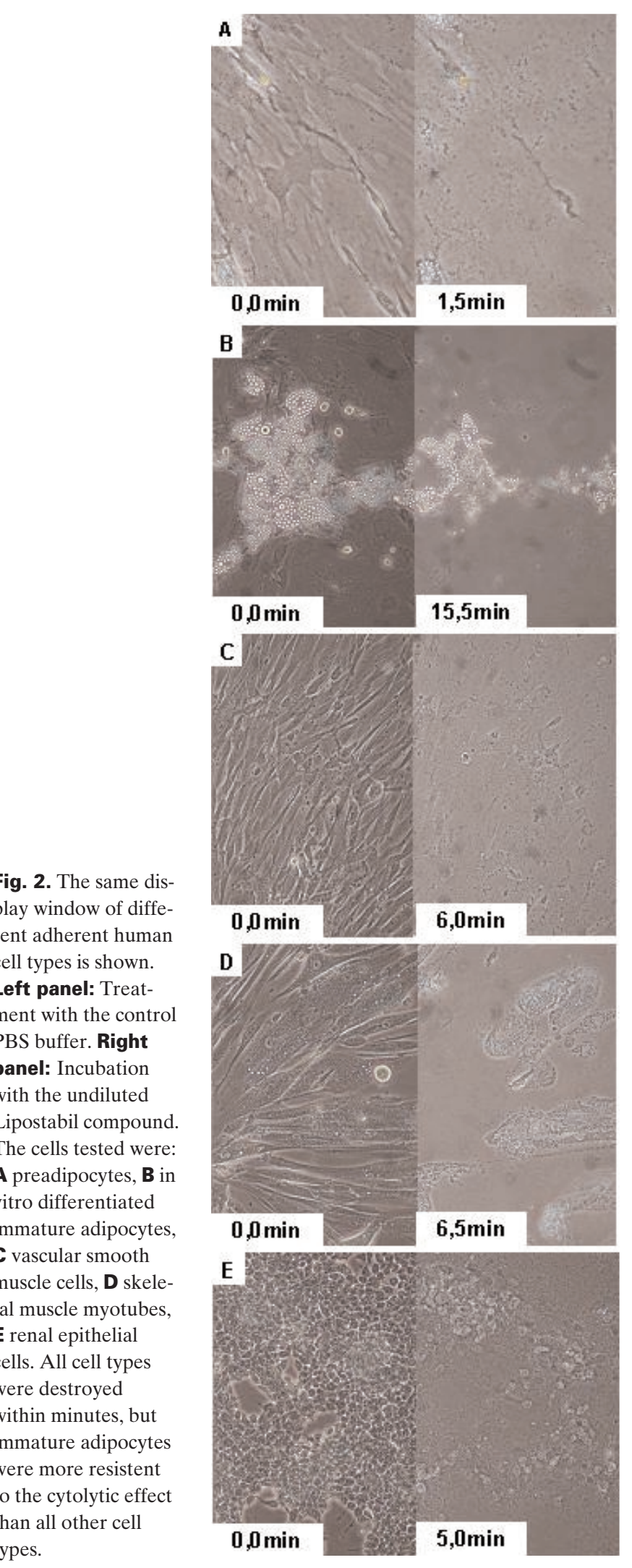

Fig. 2. The same display window of different adherent human cell types is shown. Left panel: Treatment with the control PBS buffer. Right panel: Incubation with the undiluted Lipostabil compound. The cells tested were: A preadipocytes, $\mathbf{B}$ in vitro differentiated immature adipocytes, C vascular smooth muscle cells, D skeletal muscle myotubes, E renal epithelia cells. All cell types were destroyed within minutes, but to the cytolytic effect than all other cell types.

are even smaller than applied in humans, because in the tissue, no major dilution will happen after injection, whereas in our hands the 1:8 dilution also demonstrated profound cy- tolytic activity in vitro. Surprisingly, mature adipocytes and differentiated lipid laden adipocytes were more resistant to the cytolytic effects than other human cell types such as fibroblast-like preadipocytes, vascular and skeletal muscle cells, or renal epithelial cells.

We did not determine the cytolytic effects of any single ingredient of the mixture compound because phosphatidylcholine is the main component with a significant share of $93 \%$. However, desoxycholate, a bile salt with known chemical activity as a detergent of lipid droplets and cell membranes, also demonstrated cytotoxic activity in porcine skin when compared to a common detergent used in the molecular biology laboratory, Triton-X [12]. This observation already lead to a small openlabel uncontrolled clinical study of desoxycholate injections into human lipomas [13]. The mode of action of injecting the compound into subcutaneous fat pads thus clearly is cytolysis, and the reduction of lipoma size appears to be in part due to cell destruction and in part to emulsification of released lipids that are then removed via lymphatic drainage. Whether or not injection lipolysis leads to transient increases in blood lipids remains to be speculation.

In rabbits, fat cell necrosis, granulocyte infiltration, and giant cell formation within necrotic areas were demonstrated after injection of phosphatidylcholine into anterior trunk subcutaneous fat pads some hours after injection [14]. The first systematic human studies that investigated in vivo effects of Lipostabil injection into lipomas demonstrated histological evidence of panniculitis together with fat cell destruction and blood vessel necrosis some hours after the injection $[15,16]$. During the time course of 60 days post injectionem, granulocyte infiltration decreased and macrophage infiltration increased, and this process was accompanied by enhanced fibrosis [15]. The observed panniculitis was also associated with increased cytokine mRNA expression (e.g. TNF- $\alpha$, IL-6) in the surrounding tissue [17]. Occasional case reports further signify the tissue destruction that is achieved by injection of phosphatidylcholine preparations into lipomas [18, 19]. Our in vitro data clearly support these histological descriptions by direct demonstration of cell lysis after in vitro incubation with a mixture phosphatidylcholine preparation for some minutes. Thus, another important mechanism of lipoma size reduction appears to be local inflammation and scaring within the lipoma, which appears to be difficult to control.

Surprisingly, the target cells of injection lipolysis, mature lipid filled adipocytes, are rather resistant against the cytolytic effects, and that might explain why multiple injections of the undiluted compound are needed to achieve lipoma mass reduction. Possibly, mature adipocytes are able to store some of the injected detergents within the lipid vacuole, but still most of the adipocytes died in vitro. On the other hand, our findings of highly sensitive vascular and skeletal muscle cells raise severe concerns in the case of accidental intramuscular injections. A retrospective study from the UK suggests a safe risk profile with only minor adverse drug reactions after a sur- 
vey of 10,518 treatments [20]. Unfortunately, no efficacy data were provided in this report, and no histological findings analyzed. Thus a clear risk-benefit assumption cannot be made for injection lipolysis.

In summary, injection lipolysis with phosphatidylcholine as the major compound is a highly promoted technique to reduce lipoma size mainly for aesthetic reasons. Lipoma size reduction most likely is based on cell and tissue destruction with subsequent lipid sequestration and scaring. Applying this technique currently not only means off-label use of a drug, but, even more seriously, represents application of a drug by a contraindicated route. When also taking into account the lack of a clear risk-benefit analysis due to the lack of controlled studies, the pervasiveness of injection lipolysis appears not to be justified in terms of scientific sincerity.

\section{Acknowledgement}

We thank Henning Damm for expert technical help with primary culture of human cells.

\section{Disclosure}

The authors declared no conflict of interest.

\section{References}

1 Gonzalez-Garcia R, Rodriguez-Campo FJ, SastrePerez J, Munoz-Guerra MF: Benign symmetric lipomatosis (Madelung's disease): case reports and current management. Aesthetic Plast Surg 2004;28. 108-112.

2 Cappabianca S, Colella G, Pezzullo MG, Russo A Iaselli F, Brunese L, Rotondo A: Lipomatous lesions of the head and neck region: imaging findings in comparison with histological type. Radiol Med (Torino) 2008;113:758-770.

3 Omranifard M: Ultrasonic liposuction versus surgical lipectomy. Aesthetic Plast Surg 2003;27:143-145.

4 Prado A, Andrades P, Danilla S, Leniz P, Castillo P, Gaete F: A prospective, randomized, double-blind, controlled clinical trial comparing laser-assisted lipoplasty with suction-assisted lipoplasty. Plast Reconstr Surg 2006;118:1032-1045.

5 Lesser T, Ritvo E, Moy LS: Modification of subcutaneous adipose tissue by a methylxanthine formulation: a double-blind controlled study. Dermatol Surg 1999; 25:455-462.

6 Ablon G, Rotunda AM: Treatment of lower eyelid fat pads using phosphatidylcholine: clinical trial and review. Dermatol Surg 2004;30:422-427.
7 Hasengschwandtner F: Phosphatidylcholine treatment to induce lipolysis. J Cosmet Dermatol 2005;4: 308-313.

8 Hexsel D, Serra M, Mazzuco R, Dal'Forno T, Zechmeister D: Phosphatidylcholine in the treatment of localized fat. J Drugs Dermatol 2003;2:511-518.

9 Rittes PG: The use of phosphatidylcholine for correction of localized fat deposits. Aesthetic Plast Surg 2003:27:315-318.

10 Carey GB: Mechanisms regulating adipocyte lipolysis. Adv Exp Med Biol 1998;441:157-170.

11 Janke J, Engeli S, Gorzelniak K, Luft FC, Sharma AM: Mature adipocytes inhibit in vitro differentiation of human preadipocytes via angiotensin type 1 receptors. Diabetes 2002;51:1699-1707.

12 Rotunda AM, Suzuki H, Moy RL, Kolodney MS: Detergent effects of sodium deoxycholate are a major feature of an injectable phosphatidylcholine formulation used for localized fat dissolution. Dermatol Surg 2004;30:1001-1008.

13 Rotunda AM, Ablon G, Kolodney MS: Lipomas treated with subcutaneous deoxycholate injections. J Am Acad Dermatol 2005;53:973-978.

14 Rittes PG, Rittes JC, Carriel Amary MF: Injection of phosphatidylcholine in fat tissue: experimental study of local action in rabbits. Aesthetic Plast Surg 2006; 30:474-478.
15 Bechara FG, Sand M, Hoffmann K, Sand D, Altmeyer P, Stucker M: Fat tissue after lipolysis of lipomas: a histopathological and immunohistochemical study. J Cutan Pathol 2007;34:552-557.

16 Schuller-Petrovic S, Wolkart G, Hofler G, Neuhold N, Freisinger F, Brunner F:. Tissue-toxic effects of phosphatidylcholine/deoxycholate after subcutaneous injection for fat dissolution in rats and a human volunteer. Dermatol Surg 2008;34:529-542.

17 Bechara FG, Skrygan M, Kreuter A, Altmeyer P, Gambichler T: Cytokine mRNA levels in human fat tissue after injection lipolysis with phosphatidylcholine and deoxycholate. Arch Dermatol Res 2008;300: 455-459.

18 Kopera D, Binder B, Toplak H, Kerl H, Cerroni L: Histopathologic changes after intralesional application of phosphatidylcholine for lipoma reduction: report of a case. Am J Dermatopathol 2006;28: 331-333.

19 Rose PT, Morgan M: Histological changes associated with mesotherapy for fat dissolution. J Cosmet Laser Ther 2005;7:17-19.

20 Palmer M, Curran J, Bowler P: Clinical experience and safety using phosphatidylcholine injections for the localized reduction of subcutaneous fat: a multicentre, retrospective UK study. J Cosmet Dermatol 2006;5:218-226. 